\title{
Спектры возбуждения фотолюминесценции многослойных структур с квантовыми ямами на основе гетеропары AlGaAs/GaAs для фотоприемных устройств
}

\author{
Д.А. Пашкеев ${ }^{1)}$, А.Д. Шабрин ${ }^{1)}$, В.С. Кривобок ${ }^{2)}$, И.Д. Бурлаков ${ }^{1)}$ \\ ${ }^{1}$ АО «НПО «Орион», Москва, 111538, ул. Косинская, 9 \\ ${ }^{2}$ ФГБУН Физический институт им. П.Н. Лебедева РАН, Москва, 119991, Ленинский проспект, 53 \\ тел: +7 (499) 374-8130, эл. почта: d.pashkeev@ gmail.com
}

DOI 10.34077/RCSP2019-21

Гетероструктуры с квантовыми ямами (КЯ) на основе $\mathrm{AlGaAs} / \mathrm{GaAs}\left(\mathrm{GaAs}\right.$ - яма, $\mathrm{Al}_{\mathrm{x}} \mathrm{Ga}_{1-\mathrm{x}} \mathrm{As}-$ барьер) используются для создания матричных фотоприемных устройств (ФПУ) для спектрального диапазона 8 - 12 мкм (Quantum Well Infrared Photodector, QWIP) [1]. Принцип работы QWIP ФПУ основан на межподзонных переходах электронов, локализованных на первом квантово-размерном уровне КЯ зоны проводимости (переходы с E1 на Е2). Эти уровни определяют рабочий спектральный диапазон ФПУ и зависят от технологических параметров структуры. Для оптимизации работы фотодетекторов необходим точный контроль положения этих уровней, что требует развития неразрушающих методик спектроскопического анализа выращиваемых гетероструктур [2].

В основе методики использовался метод низкотемпературного измерения спектров возбуждения фотолюминесценции (СВФ). Предварительный теоретический расчет структуры энергетических уровней в КЯ осуществлялся методом численного решения уравнения Шредингера в одночастичном приближении. Многослойные гетероструктуры выращивались методом молекулярно-лучевой эпитаксии (МЛЭ). Спектры возбуждения фотолюминесценции, а также спектры фотолюминесценции измерялись в диапазоне температур от 5 до 80 К. Для контроля спектроскопических результатов

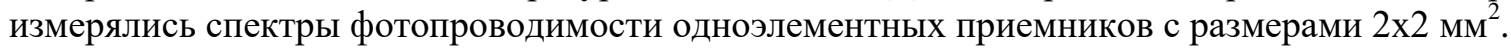

Основная идея метода СВФ состоит в последовательном измерении спектров фотолюминесценции

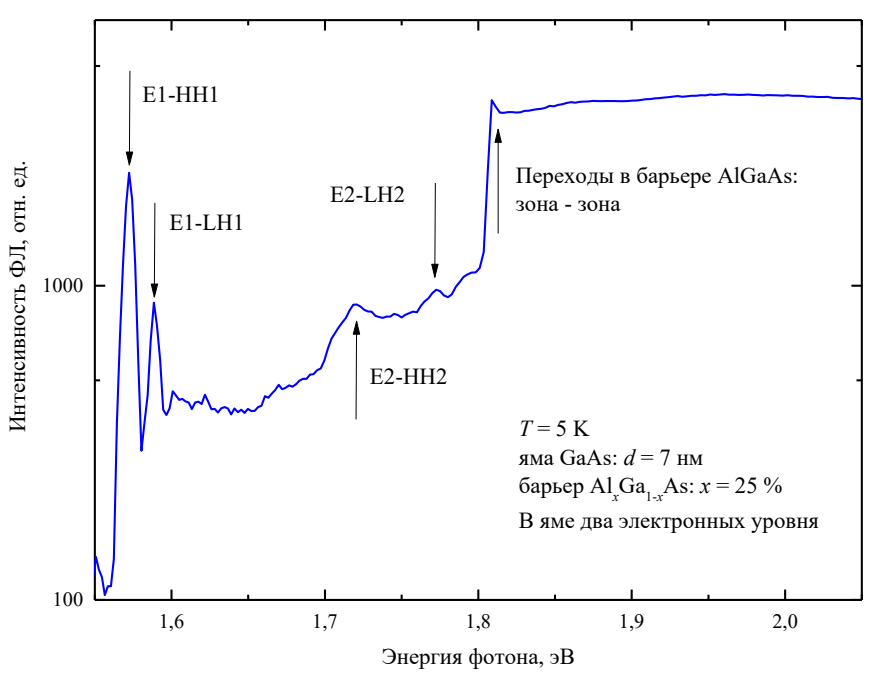
от источника возбуждения с различными длинами волн и регистрацией интенсивности основного пика излучения. В качестве перестраиваемого источника излучения использовалось излучение $\mathrm{GaN}$ светодиода, пропускаемое через монохроматор. Полуширина спектра излучения возбуждения составляла в среднем 1 нм, а шаг изменения максимума излучения - также 1 нм.

Измерения спектров проводились для образцов с различным количеством КЯ (от 1 до 10), толщин ям $d$ (от 3 до 10 нм) и содержанием AlAs в барьере $x$ от 20 до $30 \%$. На рисунке приведен измеренный спектр СВФ для структуры из 10 квантовых ям с $d \approx$ 7 нм и $x \approx 25 \%$. Стрелочками указаны наблюдаемые оптические переходы. Они формируются экситонными состояниями, соответствующим зона-зонным переходам в барьере, а также переходам между электронными уровнями (ЕХ) и дырочными уровнями (HHX - тяжелые дырки, LHX - легкие дырки). Установлено, что для КЯ с указанными диапазонами параметров энергия основного перехода (Е1-HН1) варьируется в пределах от 1,53 до 1,65 эВ для $T=5 \mathrm{~K}$, с увеличением температуры до 80 К энергии переходов изменяются в пределах 5 мэВ.

По результатам численных расчетов получено, что положение уровней LH1 и HH2 совпадает в пределах 8 мэВ, это позволяет считать, что максимум спектральной характеристики ФПУ, определяемой как E2-E1, можно рассчитать из разницы энергий переходов E1-LH1 и E2-HH2 с соответствующей поправкой. Из сравнения полученных результатов СВФ и фотопроводимости установлена корректность данного предположения, а точность определения рабочего перехода фотодетектора составляет не более 150 нм.

\section{Jumepamypa}

[1] S.D. Gunapala and etc. // IEEE Journal of Selected Topics in Quantum Electronics. 2014. V.20, № 6. P. 3802312.

[2] М.Р. Юскаев и др. // Прикладная физика. 2018. № 2. С.47-52. 